\title{
DYNAMIC CHARACTERISTICS OF A THIN FILM PC-EL SYSTEM WITH OPTICAL FEEDBACK
}

\author{
Z. PORADA \\ Institute of Electrical Engineering and Electronics, Technical University, Warszawska \\ 24, 31-15.5 Cracow, Poland \\ E. SCHABOWSKA-OSIOWSKA \\ Department of Physics and Electron Technology, Institute of Electronics, Academy of \\ Mining and Metallurgy, Al. Mickiewicza 30, 30-059 Cracow, Poland
}

(Received April 21, 1988; in final form June 10, 1988)

\section{INTRODUCTION}

The increased utilization of various optoelectronic systems has generated interests in thin film PC-El systems - a series connection of a photoconductive element (PC) with an electroluminescent cell (EL). They are frequently applied as logical gates, amplifiers of weak light signals, and because of the optical feedback in such system, they can work as bi-stable ones.

In this study a PC-EL thin film system with optical feedback, excited with a sinusoidal voltage was investigated. A cadmium sulphide thin film photoconductive element and a zinc sulphide thin film electroluminescent cell were prepared by vacuum evaporation. The input signal was in the shape of rectangular light pulses illuminating the PC element. The output signal was in the form of the light emitted from the electroluminescent cell; a part of this signal was directed to the input. For various values of system exciting voltage and for its various frequencies, the time functions of the output signal in dependence on the input signal were measured. 


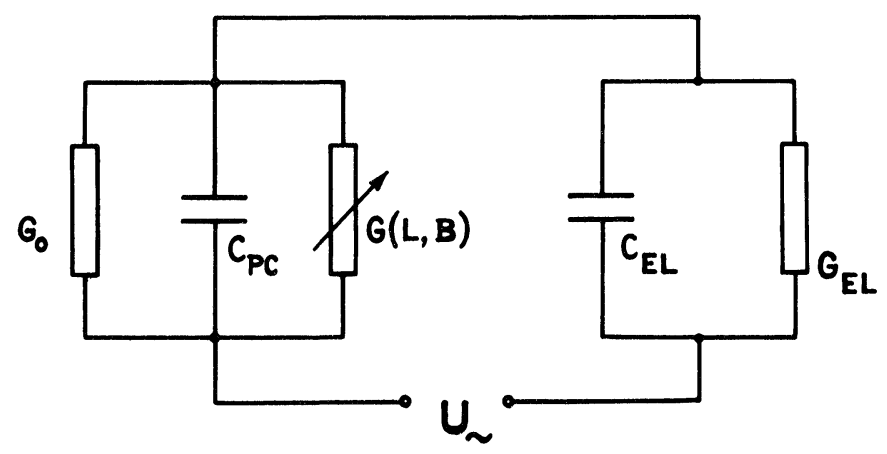

FIGURE 1 Equivalent circuit of a PC-EL system.

\section{THEORETICAL CONSIDERATIONS}

A mathematical model suitable for analyzing the dynamic properties of PC-EL system with optical feedback is proposed using the equivaluent circuit shown in Figure 1.

The instantaneous value of the current $i_{P C}$ through the photoconductive element is given by the formula ${ }^{1}$ :

$\mathrm{i}_{\mathrm{PC}}=\mathrm{C}_{\mathrm{PC}} \frac{\mathrm{d}}{\mathrm{dt}} \mathrm{U}_{\mathrm{PC}}+\left(\mathrm{G}_{\mathrm{o}}+\mathrm{g}_{1} \Delta \mathrm{n}\right) \mathrm{U}_{\mathrm{PC}}$

where $\mathrm{U}_{\mathrm{PC}}$ is the instantaneous value of the voltage on the photoconductive element, $G_{o}$ is the dark conductance of the photoconductive element, $\mathrm{C}_{\mathrm{PC}}$ is the capacitance of the photoconductive element, $\Delta \mathrm{n}$ is the density of excess carriers, and $\mathrm{g}_{1}$ is a constant parameter.

The total change in the number of excess carriers in a given time interval can be expressed as the sum of the rates of their formation and recombination ${ }^{2}$ :

$\frac{\mathrm{d}}{\mathrm{dt}} \Delta \mathrm{n}=\mathrm{G}_{\mathrm{n}}+\mathrm{R}_{\mathrm{n}}=\alpha \eta(\mathrm{L}+\beta \mathrm{B})-\frac{\Delta \mathrm{n}}{\tau}$

where $G_{n}$ is the rate of carrier formation, $R_{n}$ is the recombination rate, $\eta$ is the quantum yield, $\alpha$ is the light absorption coefficient, $\mathrm{L}$ is the external illumination, $\beta$ is the feedback coefficient determined 
by geometry and by the degree of spectral overlap of the electroluminescent cell and the photoconductive element, B is the luminance of the light emitted by an electroluminescent cell, and $\tau$ is the photoconductivity rise time.

The instantaneous value of the current $i_{\mathrm{EL}}$ through the electroluminescent cell is given by

$\mathrm{i}_{\mathrm{EL}}=\mathrm{C}_{\mathrm{EL}} \frac{\mathrm{d}}{\mathrm{dt}} \mathrm{U}_{\mathrm{EL}}+\mathrm{G}_{\mathrm{EL}} \mathrm{U}_{\mathrm{EL}}$

where $\mathrm{U}_{\mathrm{EL}}$ is the instantaneous value of the voltage in the electroluminescent cell, $\mathrm{G}_{\mathrm{EL}}$ is the leakage conductance of the electroluminescent cell, and $\mathrm{C}_{\mathrm{EL}}$ is the capacitance of the cell.

Since $\mathrm{i}_{\mathrm{PC}}=\mathrm{i}_{\mathrm{EL}}$ and $\mathrm{U}_{\mathrm{PC}}=\mathrm{U}_{\mathrm{e}}-\mathrm{U}_{\mathrm{EL}}$, where $\mathrm{U}_{\mathrm{e}}$ is the instantaneous value of the exciting voltage of the PC-EL system, the equation

$$
\begin{aligned}
& \left(C_{E L}+C_{P C}\right) \frac{d}{d t} U_{E L}+U_{E L}\left(G_{E L}+G_{o}+g_{1} \Delta n\right) \\
& =C_{P C} \frac{d}{d t} U_{e}+\left(G_{o}+g_{1} \Delta n\right) U_{e}
\end{aligned}
$$

is obtained. The instantaneous value of the luminance B of the light emitted by an electroluminescent cell ( $B$ is the output signal of the light amplifier) is given by the approximate formula ${ }^{3}$ :

$$
\mathrm{B}=\mathrm{B}_{\mathrm{o}} \exp (-\gamma \mathrm{t}) \exp \left(-\mathrm{b}\left|\mathrm{U}_{\mathrm{EL}}\right|^{-1 / 2}\right)
$$

where $B_{o}, \gamma$ and $b$ are parameters which are constant for a given electroluminescent cell.

The dependence of the luminance $B$ on the time $t$ can be calculated by using equations (2), (4) and (5).

For a calculation of the average value of the luminance $B_{a}$ for sinusoidal excitation voltage Alfrey and Taylor's formula ${ }^{3}$ was used:

$\mathrm{B}_{\mathrm{a}}=\mathrm{B}_{\mathrm{o}} \exp \left(-\frac{\gamma}{4 \mathrm{f}}\right) \exp \left(-\frac{\mathrm{b}}{\sqrt{\left|\mathrm{U}_{\mathrm{EL}}\right|}}\right)$

where $\mathrm{f}$ is the frequency of the exciting sinusoidal voltage, $\mathrm{U}_{\mathrm{EL}}=$ 
$\left|\frac{Y_{P C}}{Y_{E L}+Y_{P C}}\right| U_{o}$, and $U_{o}$ is the amplitude of the exciting voltage, $\mathrm{Y}_{\mathrm{EL}}$ is the admittance of an electroluminescent cell:

$\mathrm{Y}_{\mathrm{EL}}=\mathrm{G}_{\mathrm{EL}}+\mathrm{i} 2 \pi f \mathrm{C}_{\mathrm{EL}}$

$\mathrm{Y}_{\mathrm{PC}}$ is the admittance of a photoconductive element ${ }^{4}$ :

$\mathrm{Y}_{\mathrm{PC}}=\mathrm{G}_{\mathrm{o}}+\mathrm{g}_{\mathrm{o}}(\mathrm{L}+\beta \mathrm{B})\left(1+4 \pi^{2} \mathrm{f}^{2} \tau_{1}^{2}\right)^{-1}+\mathrm{i} 2 \pi \mathrm{fC} \mathrm{PC}_{\mathrm{PC}}$

and $\mathrm{g}_{\mathrm{o}}$ and $\tau_{1}$ are constant parameters for a given layer.

For a real PC-EL system, three additional simplifying assumptions are usually fulfilled:

$\mathrm{C}_{\mathrm{PC}} \ll \mathrm{C}_{\mathrm{EL}} ; \quad 2 \pi f \mathrm{C}_{\mathrm{EL}} \gg \mathrm{G}_{\mathrm{o}} ; \quad 2 \pi \mathrm{fC}_{\mathrm{EL}} \gg \mathrm{G}_{\mathrm{EL}}$.

Then the dependence of the average value of the luminance $B_{a}$ on the external intensity $\mathrm{L}$ of illumination can be expressed as follows:

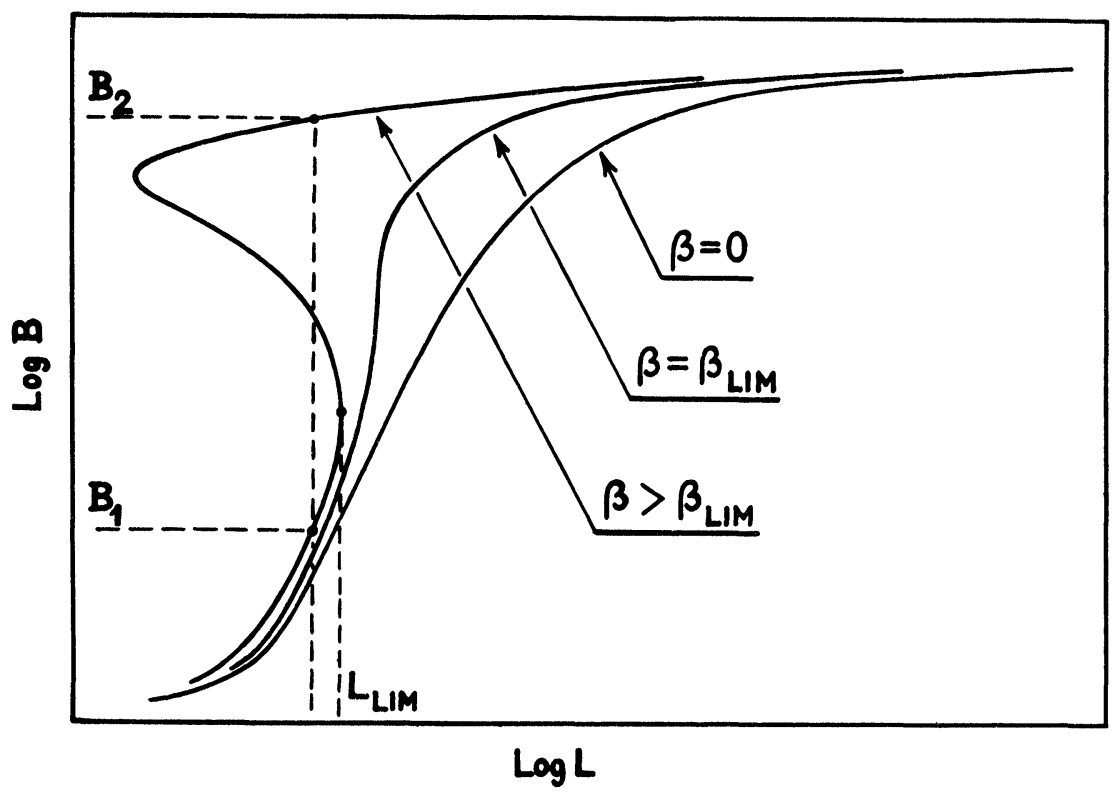

FIGURE 2 B vs. L theoretical characteristics of a PC-EL system. 
DYNAMIC CHARACTERISTICS OF A THIN FILM PC-EL SYSTEM 155

$$
\begin{aligned}
\mathrm{B}_{\mathrm{a}}= & \mathrm{B}_{\mathrm{o}} \exp \left(\frac{-\gamma}{4 \mathrm{f}}\right) \exp \left\{\frac{-\mathrm{b}}{\sqrt{\mathrm{U}_{\mathrm{o}}}}\right. \\
& \left.\times\left(1+\left[\frac{2 \pi f C_{E L}}{\mathrm{G}_{\mathrm{o}}+\mathrm{g}_{\mathrm{o}}\left(\mathrm{L}+\beta \mathrm{B}_{\mathrm{a}}\right)\left(1+4 \pi^{2} \mathrm{f}^{2} \tau_{1}^{2}\right)^{-1}}\right]^{2}\right)^{\frac{1}{4}}\right\} .
\end{aligned}
$$

Equation (9) is true for $\mathrm{G}_{\mathrm{EL}} \ll \mathrm{go}_{\mathrm{o}} \mathrm{L}\left(1+4 \pi^{2} \mathrm{f}^{2} \tau_{1}^{2}\right)^{-1}$. The characteristics calculated from equ. (9), the dependence of the luminance $B_{a}$ on the external illumination $\mathrm{L}$, are shown in Figure 2 for several values of $\beta$. It can be seen that for values of $\beta$ greater than $\beta_{\text {LIM }}$ the thin film PC-EL systems with optical feedback has a negative slope and a bistable nature.

\section{EXPERIMENTAL DETAILS AND RESULTS}

The photoconductive element (Figure 3) was prepared as a sandwichtype system on a glass substrate. The first layer was a transparent electrode of tin-doped $\operatorname{In}_{2} \mathrm{O}_{3}$, obtained by the reactive cathode sputtering of $90 \% \mathrm{In}-10 \% \mathrm{Sn}$ alloy. The second layer was a photoconductive $\mathrm{CdS}$ film ${ }^{5}$ doped with copper and chlorine and evaporated under vacuum at a pressure of $6.7 \times 10^{-3} \mathrm{~Pa}$. The thickness of the layer was $8.3 \mu \mathrm{m}$ and its recrystallization was carried out for $30 \mathrm{~min}$ at $550^{\circ} \mathrm{C}$ in air. The third layer, acting as an electrode, was produced by the vacuum evaporation of indium.

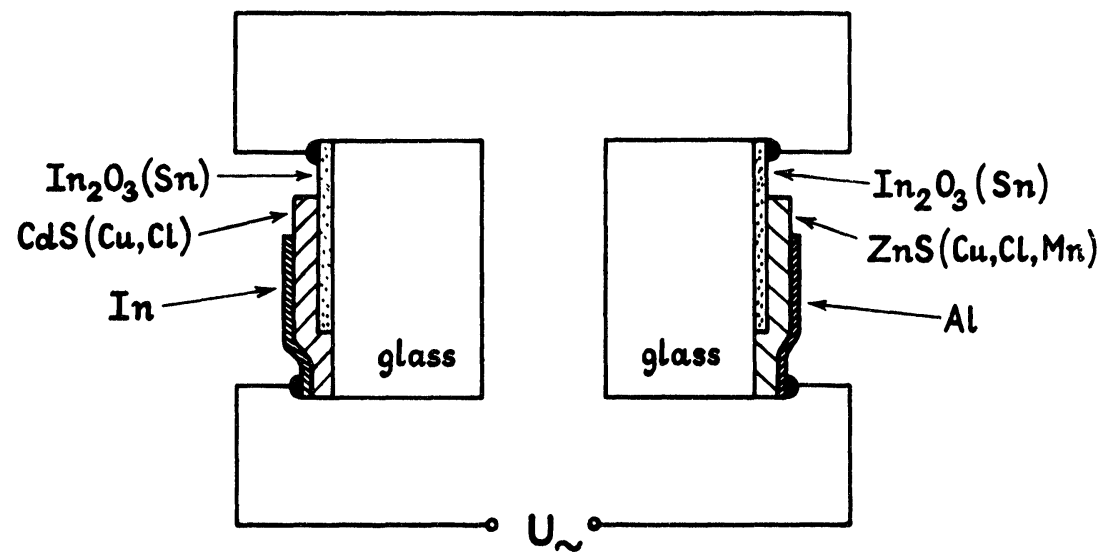

FIGURE 3 The arrangement of the thin film PC-EL system with optical feedback. 
The second component of PC-EL system, the electroluminescent cell (Figure 3), was a thin film capacitor with an average thickness of $1.08 \mu \mathrm{m}$ produced by the vacuum evaporation of copper-, chlorineand manganese-doped $\mathrm{ZnS}$. The lower transparent conducting electrode was tin-doped $\mathrm{In}_{2} \mathrm{O}_{3}$ on a glass substrate, while the upper electrode was a vacuum-evaporated thin aluminium film.

A sinusoidal voltage of fixed amplitude and frequency was applied to the PC-EL system. The luminance B of the electroluminescent cell was measured for various intensities $L$ of illumination of the photoconductive layer and for values of $\beta$ less than $\beta_{\text {LIM }}$. The results were compared with values computed using the above theoretical model. The experimental values of the parameters of the photoconductive element and the electroluminescent cell were found to be as follows: $\mathrm{G}_{\mathrm{o}}=8 \times 10^{-9} \Omega^{-1} ; \mathrm{g}_{1}=2.38 \times 10^{-7} \mathrm{~lx}^{-1} \Omega^{-1} ; \tau=$ $3.1 \times 10^{-5} \mathrm{~s} ; \mathrm{C}_{\mathrm{PC}}=6.5 \times 10^{-11} \mathrm{~F} ; \mathrm{b}=16.09 \mathrm{~V}^{1 / 2} ; \gamma=951 \mathrm{~s}^{-1}$; $\mathrm{B}_{\mathrm{o}}=104 \mathrm{~cd} . \mathrm{m}^{-2} ; \mathrm{C}_{\mathrm{EL}}=2.8 \times 10^{-9} \mathrm{~F} ; \mathrm{G}_{\mathrm{EL}}=7.4 \times 10^{-8} \Omega^{-1} ;$ and $\beta=0.78 \mathrm{~lx} \cdot \mathrm{m}^{2} \mathrm{~cd}^{-1}$.

Figure 4 shows the spectral distribution of the electroluminescence for the $\mathrm{ZnS}(\mathrm{Cu}, \mathrm{Cl}, \mathrm{Mn})$ layer and the spectral response of the $\mathrm{CdS}(\mathrm{Cu}, \mathrm{Cl})$ photoconductive layer.

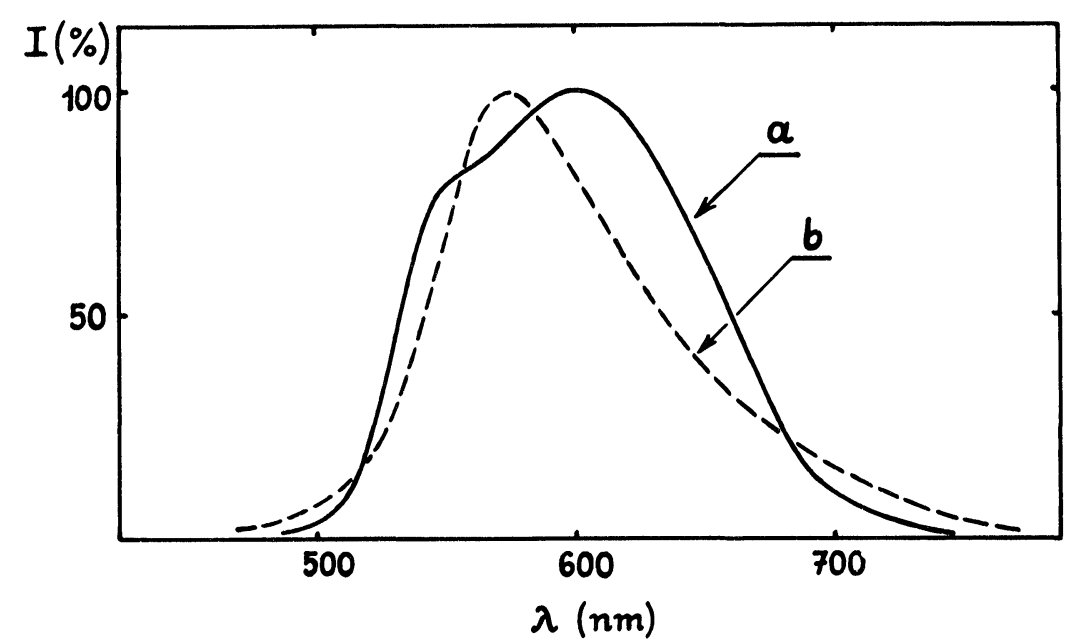

FIGURE 4 The spectral distribution $\mathrm{I}(\%)$ vs. $\lambda(\mathrm{nm})$ of the sensitivity of the $\mathrm{CdS}(\mathrm{Cu}, \mathrm{Cl})$ photoconductive layer (curve a) and of the electroluminescence of the $\mathrm{ZnS}(\mathrm{Cu}, \mathrm{Cl}, \mathrm{Mn})$ layer (curve b). 
Rectangular pulses of the light illuminating the photoconductive element were applied to the input of the PC-EL system and the output signal was the luminance $B(t)$ of the light emitted from the electroluminescent cell. The frequency of the light pulses at the input was $140 \mathrm{~Hz}$.

Figure 5 shows the time-dependence of luminance for an applied voltage of amplitude $280 \mathrm{~V}$ at a frequency of $500 \mathrm{~Hz}$, at illumination of the photoconductive element with light pulses of $0.5 \mathrm{~lx}$ for a PCEL system of feedback coefficient $\beta=2.0 \mathrm{~lx} \cdot \mathrm{m}^{2} . \mathrm{cd}^{-1}$. The illumination intensity was lower than the limiting illumination $\left(\mathrm{L}_{\mathrm{LIM}}=0.76 \mathrm{~lx}\right)$.

Above $\mathrm{L}_{\mathrm{LIM}}$, the system acted as a bi-stable system, and the dependence of the luminance $\mathrm{B}$ on time is shown in Figure 6 at fixed remaining parameters. As can be seen, the investigated PC-EL system has two stable work points - for the illumination $\mathrm{L}=0.8 \mathrm{~lx}$, $\mathrm{B}_{1}=0.4 \mathrm{~cd} \cdot \mathrm{m}^{-2}$ and $\mathrm{B}_{2}=23 \mathrm{~cd} . \mathrm{m}^{-2}$.

From a theoretical analysis, the limiting value of the optical feedback coefficient $\left(\beta_{\text {LIM }}\right)$ depends on the frequency as shown in Figure 7. The limiting value of illumination intensity above which the system acts as a bi-stable one (if $\mathrm{O}<\mathrm{L}<\mathrm{L}_{\text {LIM }}$, the system is mono-stable, when $\mathrm{L}>\mathrm{L}_{\mathrm{LIM}}$ - bi-stable), appears to be a significant parameter from the point of view of applications. The dependence of this value of input signal $\mathrm{L}_{\mathrm{LIM}}$ on the frequency is given in Figure 8 .
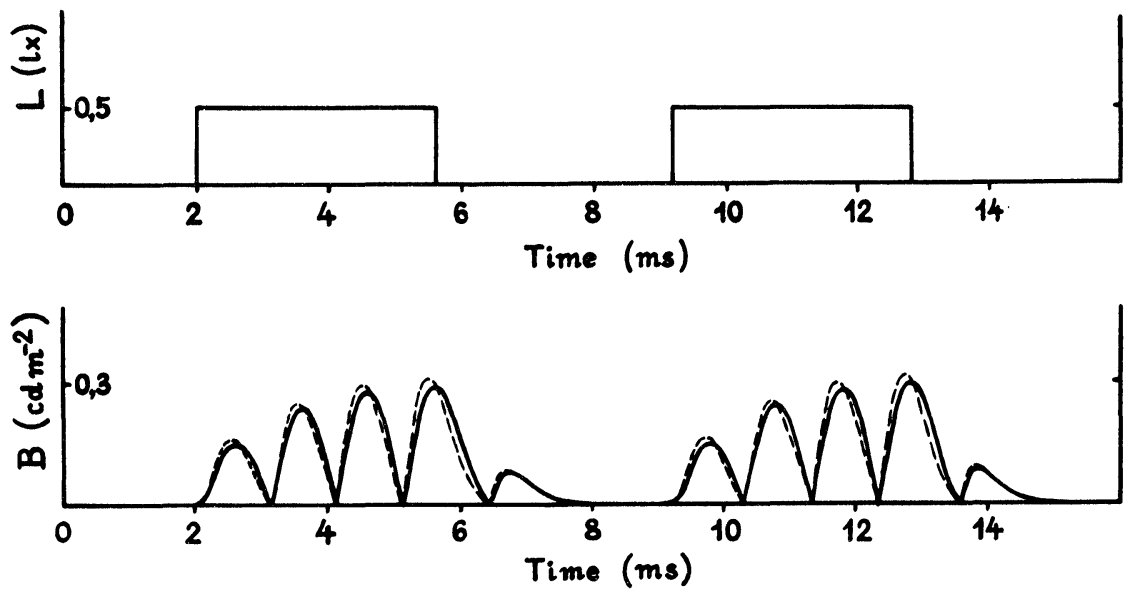

FIGURE 5 Luminance vs. time for a frequency of $500 \mathrm{~Hz}$ and an amplitude of $280 \mathrm{~V}$ (— experimental results, ------ values calculated using the theoretical model). 

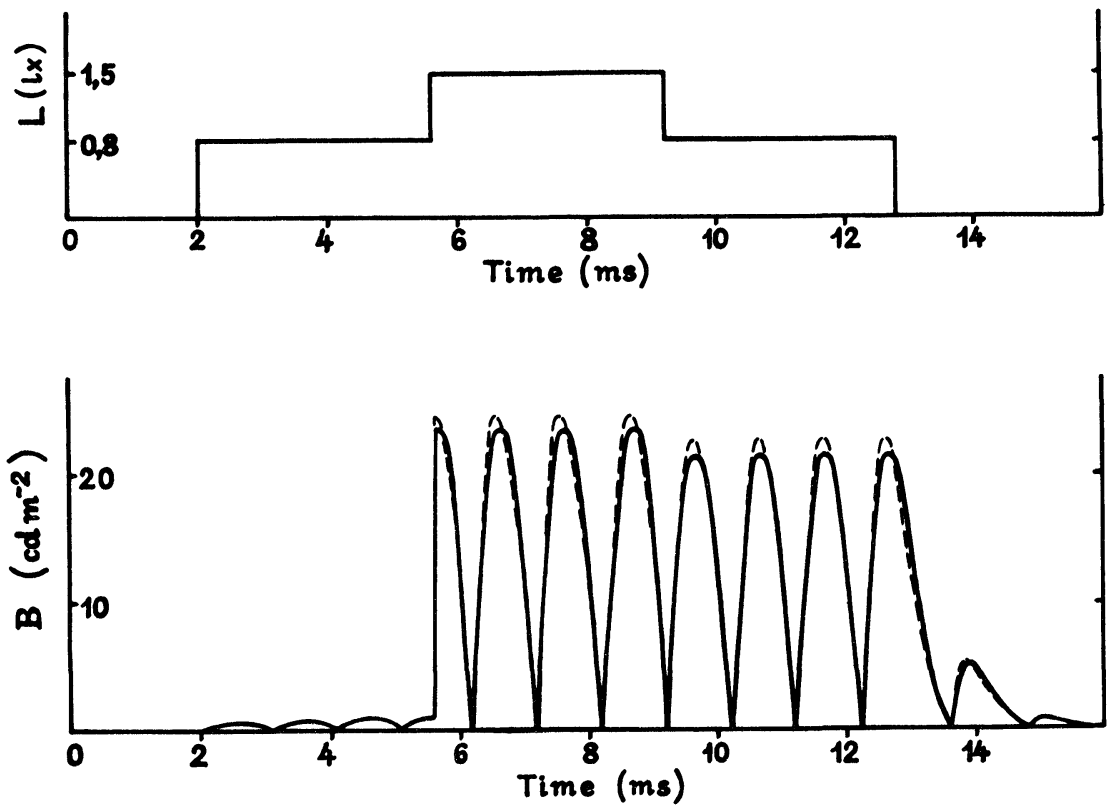

FIGURE 6 Dependence of the luminance B on time for illuminations $0.8 \mathrm{~lx}$ and 1.5 Ix (— experimental results, ------ values calculated using the theoretical model).

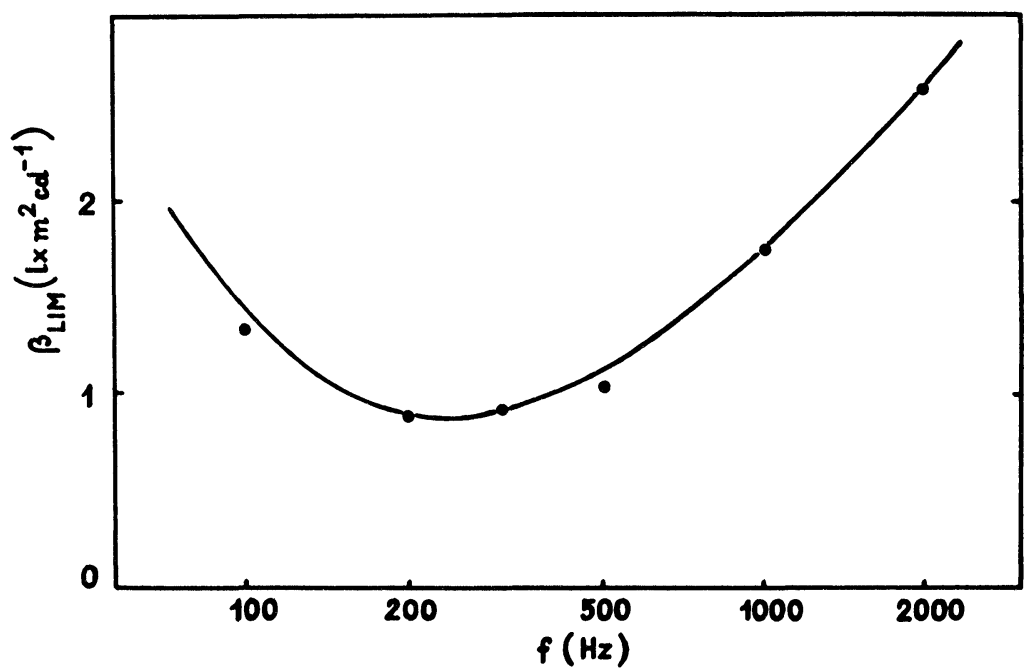

FIGURE 7 Dependence of the coefficient $\beta_{\text {LIM }}$ on the frequency. 


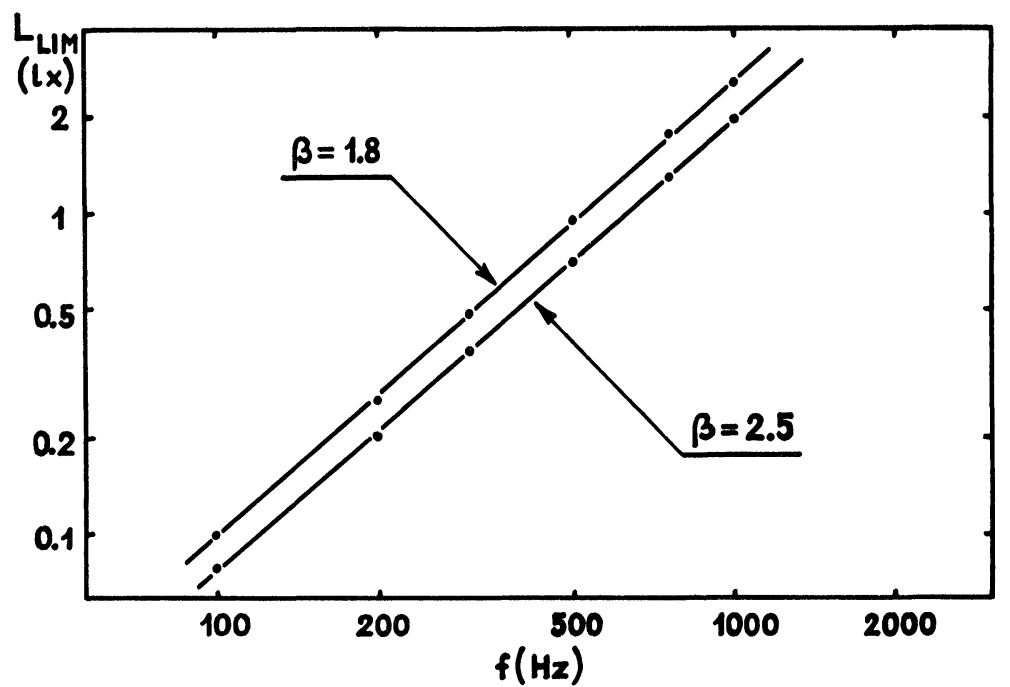

FIGURE 8 Dependence of the limiting value of illumination intensity on the frequency.

\section{CONCLUSIONS}

Both the measurements and the analysis of the proposed theoretical model show that the output signal, i.e. the luminance $B(t)$ of the light emitted by the electroluminescent cell, exhibited a periodic function. For a PC-EL system excited by a sinusoidal voltage, the frequency $f_{B}$ of the output signal was $2 f_{o}$, where $f_{o}$ is the frequency of the exciting voltage.

For low frequencies of the exciting voltage $\left(50 \mathrm{~Hz}<\mathrm{f}_{\mathrm{o}}<200 \mathrm{~Hz}\right)$ the shape of the curves of time dependences of the luminance $\mathrm{B}(\mathrm{t})$ varied with the frequency $f_{o}$, while for high frequencies $\left(f_{o}>500 \mathrm{~Hz}\right)$ the shape of the curves of luminance versus time showed almost no change.

A thin film PC-EL system can be of bi-stable nature only when its optical feedback coefficient exceeds the limiting value $\beta_{\text {LIM }}$. The value of the coefficient $\beta_{\text {LIM }}$ varied with frequency and for the investigated system attained the lowest value $\left(0.8 \mathrm{~lx} \cdot \mathrm{m}^{2} \cdot \mathrm{cd}^{-1}\right)$ for the frequency of $300 \mathrm{~Hz}$. The investigated PC-EL system has two stable 
work points, on condition that input signal $\mathrm{L}$ exceeds limiting value of luminance $\mathrm{L}_{\mathrm{LIM}}$.

All the obtained experimental results showed a good agreement with the characteristics derived from the proposed theoretical model.

\section{REFERENCES}

1. Z. Porada, Thin Solid Films, 125, 341 (1985).

2. P.S. Kireev, Semiconductor Physics, Mir, Moscow 1978 (English translation).

3. G.F. Alfrey and J.B. Taylor, Br. J. Appl. Phys., 4, 44S (1955).

4. Z. Porada, Thin Solid Films, 109, 213 (1983).

5. Z. Porada and E. Schabowska, Thin Solid Films, 66, L55 (1980). 

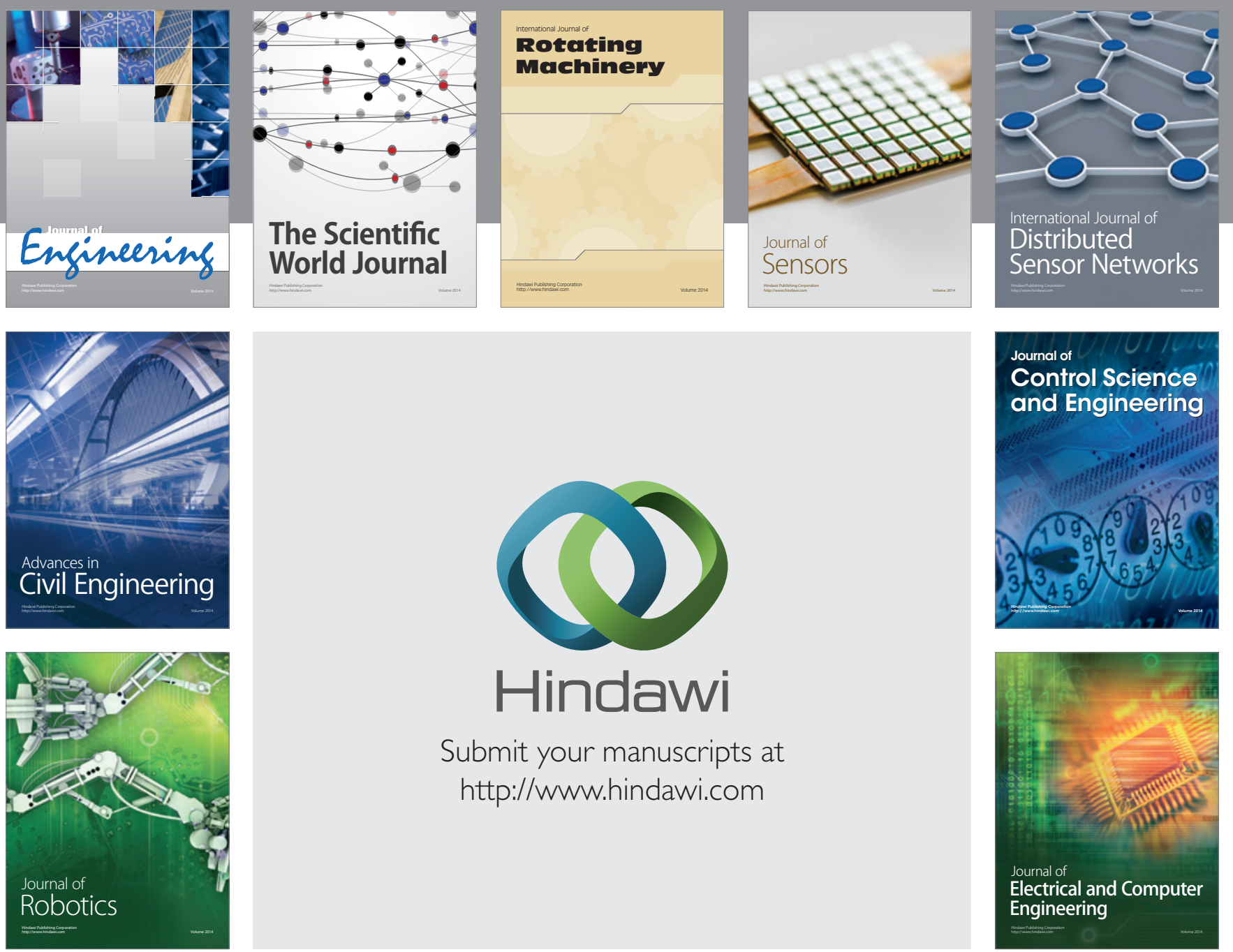

Submit your manuscripts at

http://www.hindawi.com
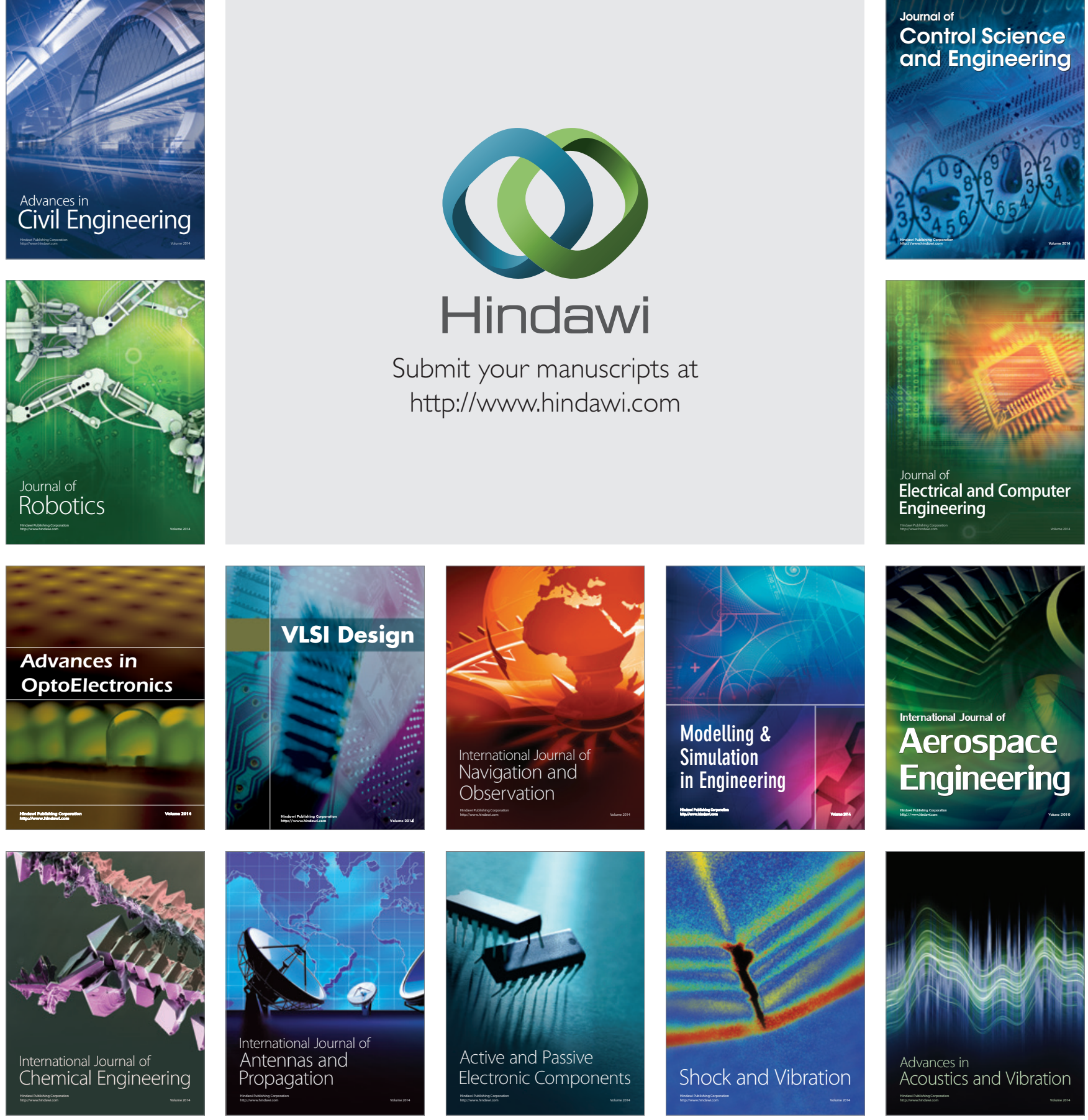